Peer Reviewed Paper openaccess

\title{
Terahertz spectroscopy and imaging for gastric cancer diagnosis
}

\author{
Faustino Wahaia, ${ }^{\mathrm{a}, *}$ Irmantas Kašalynas, ${ }^{\mathrm{b}}$ Linas Minkevičius, ${ }^{\mathrm{b}}$ Catia D. Carvalho Silva, ${ }^{\mathrm{c}}$ Andrzej Urbanowicz ${ }^{\mathrm{b}}$ and \\ Gintaras Valušis ${ }^{\mathrm{b}}$
}

\author{
anniversidade do Porto, Porto, Portugal. E-mail: fwahaia@fc.up.pt \\ bDepartment of Optoelectronics, Center for Physical Sciences and Technology, Vilnius, Lithuania \\ ${ }^{c}$ Centro Hospitalar São João, Porto, Portugal
}

ORCID iDs

F. Wahaia: https://orcid.org/0000-0001-8920-1383

I. Kašalynas: https://orcid.org/0000-0003-1256-9424

A. Urbanowicz: https://orcid.org/0000-0002-2769-452X

L. Minkevičius: https://orcid.org/0000-0002-3831-8976

Gintaras Valušis: https://orcid.org/0000-0002-7076-6840

\begin{abstract}
Terahertz waves are sensitive to differences in biological tissue hydration, we present promising results regarding the feasibility of applying this with terahertz time-domain spectroscopy and imaging for early detection of cancer through the characterisation of human gastrointestinal tissue with cancer-affected regions. To do that, healthy (normal) and carcinoma-affected gastric tissue samples at different stages were measured using transmission terahertz time-domain spectroscopy in the frequency range of 0.15-2.00 THz. Absorption coefficients and refractive index spectra of both normal and carcinoma-affected tissue were extracted and analysed. The results confirm that the techniques may be powerful tools to perform qualitative, early diagnosis of human cancer.
\end{abstract}

Keywords: gastrointestinal tract, gastric carcinoma, tumour staging, terahertz waves, terahertz spectroscopy and imaging

\section{Introduction}

According to global cancer data, the cancer burden rose to 18.1 million new cases and 9.6 million cancer deaths in 2018; ${ }^{1}$ the commonest type of cancer is gastrointestinal (Gl). Its early diagnosis is crucial for in-time treatment of affected patients. Several techniques, such as $X$-ray imaging, magnetic resonance imaging, tissue biopsy etc., are presently being used and are under continuous investigation for this purpose. However, there are still many challenging issues to overcome, as it is difficult to diagnose the disease's presence in its very early stages and/or to distinguish between benign and dysplastic tumours. Terahertz ( $\mathrm{THz}$ ) spectroscopy and imaging seem to be powerful options to add to this collection of diagnostic tools contributing to a solution for the important health and social problems associated with cancer.

Terahertz time-domain spectroscopy (TTDS) and imaging are attracting worldwide interest for their application in biomedicine, such as for the characterisation
Correspondence

Faustino Wahaia (fwahaia@fc.up.pt)

Received: 17 October 2019

Revised: 9 December 2019

Accepted: 10 December 2019

Publication: 1 January 2020

doi: 10.1255/jsi.2020.a2

ISSN: 2040-4565

\section{Citation}

F. Wahaia, I. Kašalynas, L. Minkevičius, C.D. Carvalho Silva,

A. Urbanowicz and G. Valušis, "Terahertz spectroscopy and imaging for gastric cancer diagnosis", J. Spectral Imaging 9, a2 (2020).

https://doi.org/10.1255/jsi.2020.a2

(c) 2020 The Authors

This licence permits you to use, share, copy and redistribute the paper in any medium or any format provided that a full citation to the original paper in this journal is given, the use is not for commercial purposes and the paper is not changed in any way. 
of biomolecules, ${ }^{2}$ DNA/RNA, amino acids/peptides, proteins, ${ }^{3}$ cells and tissues, including studies of different types of biomaterials. ${ }^{4,5}$ The techniques are also important in a wide spectrum of applications, including homeland security, ${ }^{6-9}$ law enforcement, ${ }^{10}$ restoration of cultural heritage, ${ }^{11,12}$ and for quality control of pharmaceuticals and identification of their counterfeiting. . $^{13,14}$

The promising results on the use of the techniques, particularly in the biomedical area, ${ }^{15-17}$ have fostered the large-scale research activity of many groups worldwide. However, besides the previously mentioned issues, there are others that are challenging at the fundamental technological level: in understanding the interaction of $\mathrm{THz}$ waves with biological media, including appropriate safety guidelines. The fact that materials such as paper, vinyl, plastics, textiles, ceramics, semiconductors, lipids and powders are transparent to $\mathrm{THz}$ waves makes the $\mathrm{THz}$ region a good candidate for the above applications. Furthermore, $\mathrm{THz}$ waves do not present risks due to irradiation.

In the specific case of cancer diagnosis, there is a growing interest in exploring the $\mathrm{THz}$ spectrum. Its usage in medical imaging has certain advantages compared to $X$-rays, such as its considerably lower energy than the ionisation energy of biological molecules, coupled with the fact that the rotational and vibrational modes of water molecules lie within the $\mathrm{THz}$ spectral region, contributing to a high sensitivity. The feasibility of using $\mathrm{TH} z$ waves to detect human tumour tissues by monitoring cell density and changes in water content has been reported recently. ${ }^{18-20}$ The tumour environment usually generates increased blood supply to affected tissues and a consequent local increase in tissue water content. With the growth of tumours, the central cells no longer receive nutrients from the healthy blood vessels and, therefore, new blood vessels are formed. This could contribute to the contrast observed in $\mathrm{THz}$ cancer diagnosis. Moreover, conformational modes of water and biomolecules for this frequency region, as well as structural changes occurring in diseased tissue, have also been observed or suggested by several research groups to be contrast-contributing factors. ${ }^{21-23}$

Additionally, the high sensitivity of $\mathrm{THz}$ waves makes this technique suitable not only for the discrimination of abnormal from normal tissue, but also of benign from malignant tumours. This is achieved through differences in the interstitial water content in the tissue, due to the fact that the water-bound state is different in the two types of cancer. ${ }^{15,24,25}$
Malignant tumours are made up of cells that grow out of control, which can invade nearby tissues and spread to other parts of the body, moving away from the original (primary) tumour site and spreading to other organs. There, they can continue to grow and form another tumour on new sites, which is known as metastasis or secondary cancer. ${ }^{26}$ Taking into account the unique features of $\mathrm{THz}$ technology, i.e. strong sensitivity to the presence of free or bound water, it can be seen how differentiation of the two types of tumour is possible. ${ }^{27}$

In previous works, we have investigated the potential of $\mathrm{THz}$ imaging and spectroscopy for the detection of dehydrated, paraffin-embedded, colorectal and gastric tissues. Essentially, these studies have shown that contrast between normal and tumour tissues could be detected, further indicating that other tissue elements contribute to the contrast observed rather than just water. ${ }^{28-30}$

The present work is aimed at demonstrating the capability of a compact $\mathrm{THz}$ spectrometer (a fibre-coupled $\mathrm{THz}$ spectrometer) to establish contrast between normal and gastric-carcinoma-affected freshly excised tissue. This research work is one of the few studies carried out on carcinoma-affected human stomach tissue by $\mathrm{THz}$ spectroscopy. Hou et al. ${ }^{31}$ have studied dehydrated gastric tissue using $\mathrm{THz}$ spectroscopy and found differences in absorption spectra between normal and tumoural tissue, confirming that the intrinsic increase of hydration in cancer-affected tissues could be the main $\mathrm{THz}$ contrastcontributing factor.

\section{Materials and methods Tissue sample preparation}

A set of 15 anonymous samples of human gastric tissues, comprising normal and carcinoma-affected areas, was obtained from the Department of Pathologic Anatomy of Centro Hospitalar São João (Porto, Portugal). The tissues were donated for lab use and prepared under the approval of the Ethics Commission of Centro Hospitalar S. João - EPE, (Ref. CES 211-13).

Histological samples with constant thickness of $0.50 \mathrm{~mm}$ were taken from partial distal and total gastrectomy specimens. They had been previously analysed, classified and staged as gastric adenocarcinomas pT3 and pT4. Those staged as pT3 corresponded to a tumour penetrating sub-serosal connective tissue without invasion of visceral peritoneum or adjacent structures. ${ }^{32,33}$ Those staged as 
PT4 corresponded to a tumour which had invaded the serosa (visceral peritoneum). ${ }^{32}$ The tissue samples were prepared according to standard protocols approved at the Centro Hospitalar S. João, Porto. Briefly the procedures for collection and preparation of tissue samples consisted of three steps: 1) tissue collection, preparation and fixation; 2) selection of samples from the tissue; and 3) processing of the sample.

The normal and carcinoma-affected areas in each sample had been previously identified by histological examination (Figure 1).

Before starting any measurements, samples were sandwiched between two $1 \mathrm{~mm}$ thick and $20 \times 20 \mathrm{~mm}$ sized high-density polyethylene (HDPE) plates, separated with spacers of $0.50 \mathrm{~mm}$. The tissue was slightly pressed between the two plates in order to avoid air gaps between the sample surface and the HDPE surface.

\section{THz spectroscopic analyses}

A fibre-coupled $\mathrm{THz}$ spectrometer (model T-Fiber, Teravil Co., Vilnius, Lithuania) was used for the measurements. The spectrometer has an integrated femtosecond fibre laser with two fibre output ports. The femtosecond laser with fast delay line and signal registration electronics is integrated in a single compact housing with a footprint of $40 \times 40 \mathrm{~cm}$. The fast delay line allows real time data acquisition with a speed of 10 spectra s$^{-1}, 110$ ps time window and a spectral resolution $<10 \mathrm{GHz}$. The transceiver (emitter and detector) is fibre-coupled to the femtosecond laser. The laser is a LightWire FF50 (EkSPLA), with $1064 \mathrm{~nm}$ central wavelength, and a pulse duration of $<160 \mathrm{fs}$,
$60 \mathrm{~mW}$ output power, $40 \mathrm{MHz}$ pulse repetition rate and $0.15-3.00 \mathrm{THz}$ frequency range. The TTDS and imaging measurements were performed in randomly chosen zones of the same samples. All the samples were measured at the room temperature under the same conditions and mechanical positioning.

\section{Tissues parameter extraction}

Several authors have presented material parameter extraction algorithms to determine the complex refractive indices of samples with TTDS. ${ }^{34,35}$ For that purpose, a $\mathrm{THz}$ pulse propagating through a sample is compared to another $\mathrm{THz}$ pulse propagating without the sample in its path. This was achieved by tracing the temporal shape of the electric field with sample, $E_{s}(t)$, and without sample, $E_{\text {ref }}(t)$, where $t$ is the optical delay time. These two pulses are transformed into the frequency domain using a fast Fourier transform (FFT) to obtain the complex transmission spectra for the signal, $E_{s}(\omega)$, and for the reference (HDPE only), $E_{\text {ref }}(\omega)$. Considering normal incidence, the ratio of these fields is related to the absorption coefficient $\alpha(\omega)$ and refractive index $n(\omega)$ of the sample as follows, ${ }^{36,37}$

$$
\frac{E_{s}(\omega)}{E_{r e f}(\omega)}=\frac{1}{4 n(1+n)^{2}} \exp \left(\frac{\kappa \omega d}{c(n-1)}\right)=A(\omega) \exp [-\kappa \phi(\omega)]
$$

where $\omega$ is the frequency, $c$ is the speed of light in a vacuum, $d$ is the thickness of the sample, $A(\omega)$ is the amplitude ratio between the spectrum of the sample signal and that of the reference, and $\Delta \varphi(\omega)$ is the relative phase difference. From Equation (1), the optical constants of the tissue were calculated, and, therefore,
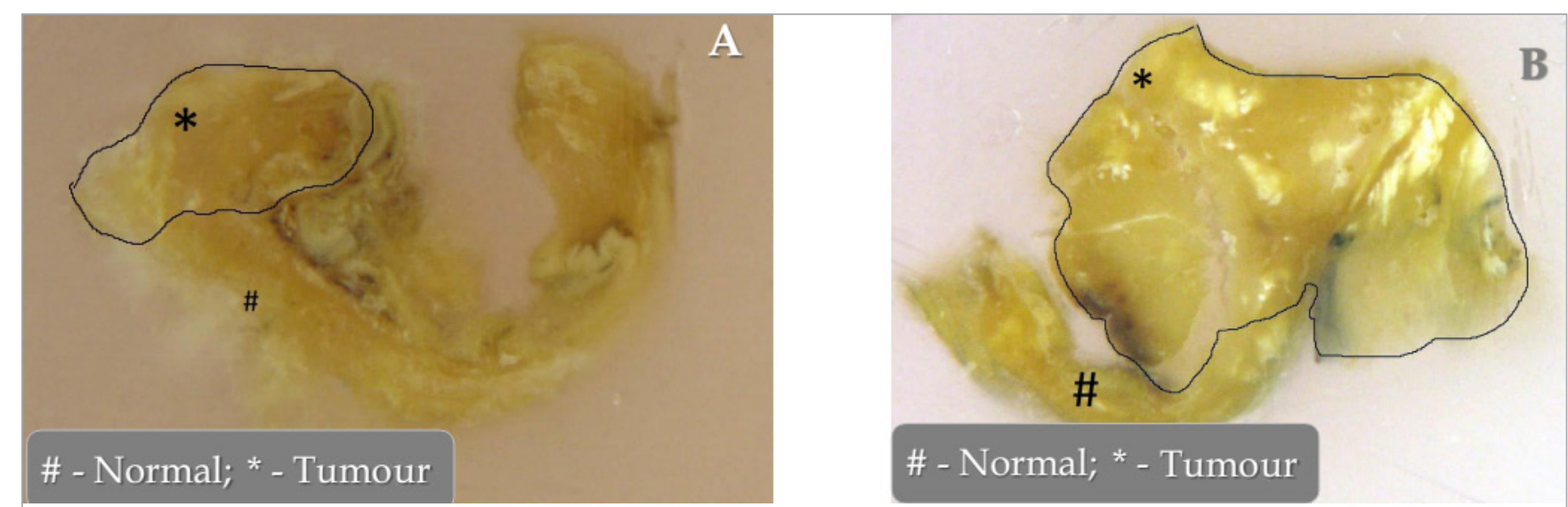

Figure 1. Macroscopic images of samples from different stages of gastric carcinoma. (A) pT3 stage and (B) a pT4 stage carcinoma. 
the refractive index and the absorption coefficient were determined using the following equations, $34,35,38$

$$
\begin{gathered}
n_{\text {samp }}(\omega)=[c \Delta \phi(\omega) / \omega d]+n_{\text {ref }} \\
\alpha_{\text {samp }}(\omega)=2 d^{-1} \ln \left\{4 n_{\text {samp }}(\omega) / A(\omega)\left[n_{\text {samp }}(\omega)+n_{\text {ref }}\right]^{2}\right\}
\end{gathered}
$$

where $k(\omega)$ is the attenuation coefficient, which is the imaginary part of the complex refractive index, $\tilde{n}(\omega)=n_{s}(\omega)-i \kappa(\omega)$. From the recorded pulses, $A(\omega)$ and $\varphi(\omega)$ were directly obtained through FFT operation.

\section{Results and discussion}

A comparison was made in terms of the attenuation of absorption functions due to water and bio-structural alterations due to the tissue pathologic stage between normal, and pT3 and pT4 development stages. It allowed us not only to discriminate the three phases and their exact margins, but also to achieve early diagnosis by detecting initial differences between the malignant and benign phase.

In this study, the working frequency range was restricted to between $0.15 \mathrm{THz}$ and $2.00 \mathrm{THz}$ due to the relatively high noise level on both sides of the working range (before $0.15 \mathrm{THz}$ and after $2.00 \mathrm{THz}$ ).

In Figure 2, a slight contrast between the normal (healthy) regions and those in tissue pathological stage pT3 as well as that in stage pT4 can be observed. In turn, one can also observe a slight contrast between the two pathological stages pT3 and pT4. For example, at a frequency of $2 \mathrm{THz}$, the absorption coefficient value for the normal tissues varies between $90 \mathrm{~cm}^{-1}$ and $110 \mathrm{~cm}^{-1}$ from the regions of samples with pathological stages $\mathrm{pT} 3$ and $\mathrm{p} T 4$, respectively.

In previous studies on dehydrated gastric tissue, ${ }^{29}$ we observed very low contrast, a fact that was explained by the absence of water, which intensifies the contrast due to its strong absorption in the $\mathrm{THz}$ frequency region. As was found by other research groups, ${ }^{18,39}$ refractive indices and absorption coefficients of tumour tissue are higher than those of normal tissue. This occurs because tumour tissue tends to have slightly higher water content compared with normal. HDPE has low absorption and no dispersion at working frequencies and, therefore, losses due to this medium had no significant impact on the results. Other factors on dehydrated samples, namely conditions within the tumour microenvironment, rapid and uncontrolled cell division leading to an increased cell density and/or to the presence of certain proteins, factors associated with the differences caused by cell iterations and abnormal proteins, increase in the vascularisation around tumours and the intrinsic release of growth factors, contributed to the observed contrast, although at lower percentages.

Terahertz imaging is able to provide a greater spatial resolution, up to tens of microns. Therefore, THz imaging can, in support of spectroscopy, be used to assess both the structure and the attenuation performance of bio-tissue samples by recording the image at selected frequencies where optical constants differ considerably. The imaging was performed with a VDI (Virginia Diodes, Inc.) electronic multiplier chain driven by the synthesiser and producing $580-620 \mathrm{GHz}$ radiation. Radiation was electrically modulated at a frequency of $2 \mathrm{kHz}$.

The beam was collimated by a Teflon lens with $12 \mathrm{~cm}$ focal length distance and $5 \mathrm{~cm}$ diameter. The collimated beam was angled with a $5 \mathrm{~cm}$ mirror in order to extract just the central area of the emitted beam and directed to the investigated sample by a $5 \mathrm{~cm}$ focal length off-axis parabolic mirror. The transmitted and reflected radiation was also collected using parabolic mirrors and focused to the titanium microbolometer detector. ${ }^{39}$ We estimated that a distance of $1 \mathrm{~m}$ between the $\mathrm{THz}$ source and the flat mirror was required for far field radiation conditions. The titanium microbolometer was chosen for $\mathrm{THz}$ radiation detection as it possesses a small effective-antenna cross-section, enabling a high-resolution scan of a local intensity. ${ }^{40}$ The signals were registered with a lock-in amplifier and processed with a computer. Samples were scanned by moving them on two translational stages along the $x-y$ axes.

Figure 3 displays the $\mathrm{THz}$ imaging results for one of the samples, obtained at $0.58 \mathrm{THz}$. The randomly selected tissue for imaging appeared to be opaque in the transmission experiments. However, the image in reflection shows a reasonable contrast between the zones of affected and normal tissue (scales in the change of the signal are shown on the left axis in all panels). Diseased zones can be clearly seen as areas demonstrating higher reflectance (red colour). The low contrast can be explained by the fact that measurements were performed directly on an irregular surface of the tissue, producing $\mathrm{THz}$ wave scattering. The selection of only one sample for imaging was intended to show the differences between affected and normal (healthy) regions in the same sample. 

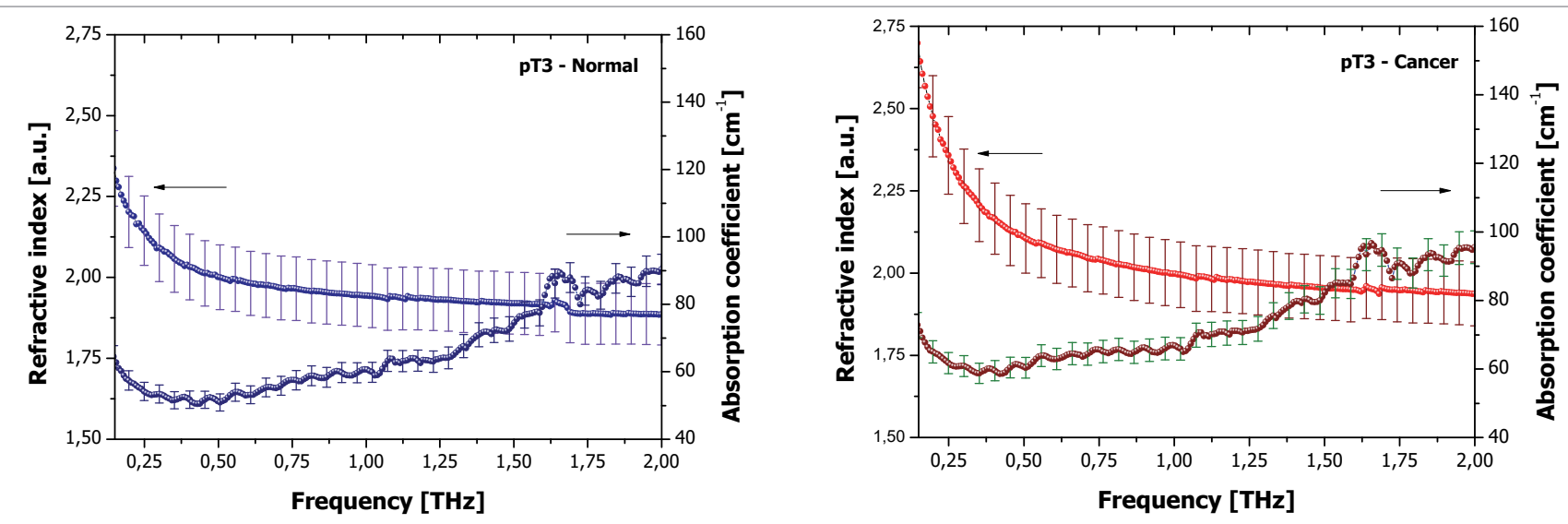

(pT3)
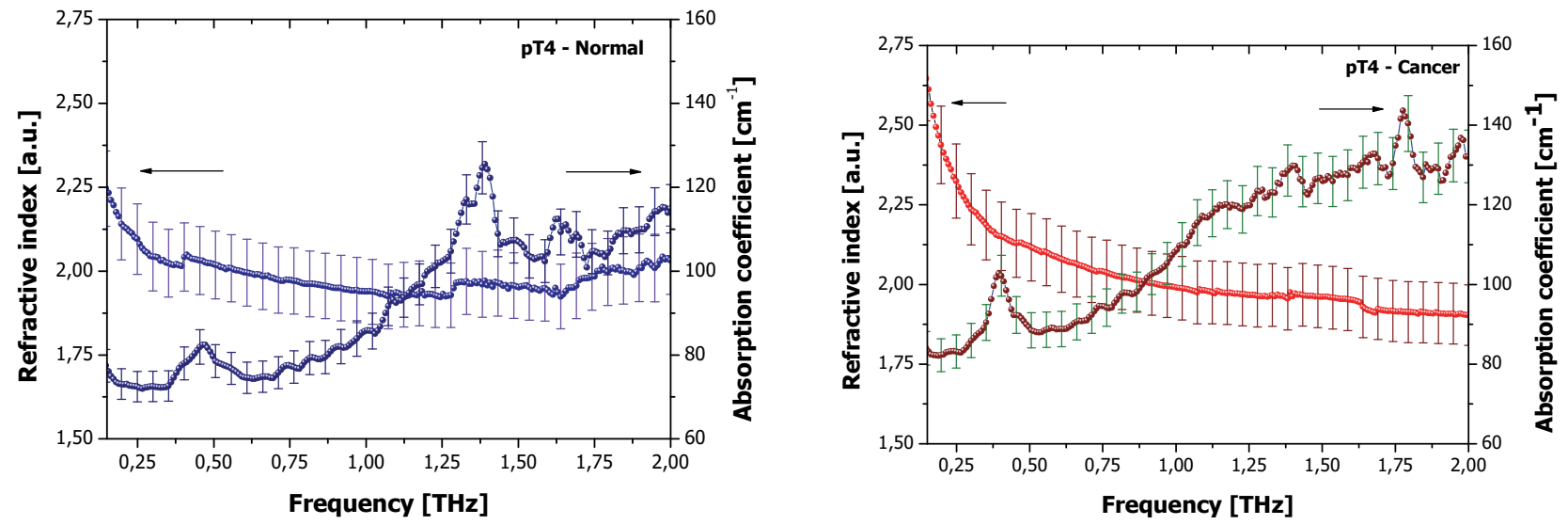

$(\mathrm{pT} 4)$

Figure 2. The absorption coefficients and refractive indices spectra in both, normal and tumour tissue for pT3 and pT4.

The contrast between affected and normal tissue regions is resolved in the reflection image, indicating different water content in the sample. This illustrates that $\mathrm{THz}$ imaging can successfully be employed for cancer diagnosis in very early phases.

\section{Conclusions}

In the present study, two groups of human normal and tumoural gastric tissue, taken from a section with the same bio-structural typology, were investigated. Using TTDS, we have shown that carcinoma regions of all samples intrinsically show higher absorption coefficients and refractive indices, allowing them to be distinguished from the normal regions of the samples. These findings, together with those observed using $\mathrm{THz}$ imaging, may take us a step closer to early cancer detection. Thereby, the techniques (TTDS and THz imaging), after exhaustive and accurate experimental work, could be good candidates as complementary tools to those already used in cancer diagnosis.

\section{Acknowledgements}

The authors gratefully acknowledge financial support for this work, from BM1205 COST Action, for a Short Term Scientific Mission Grant. 


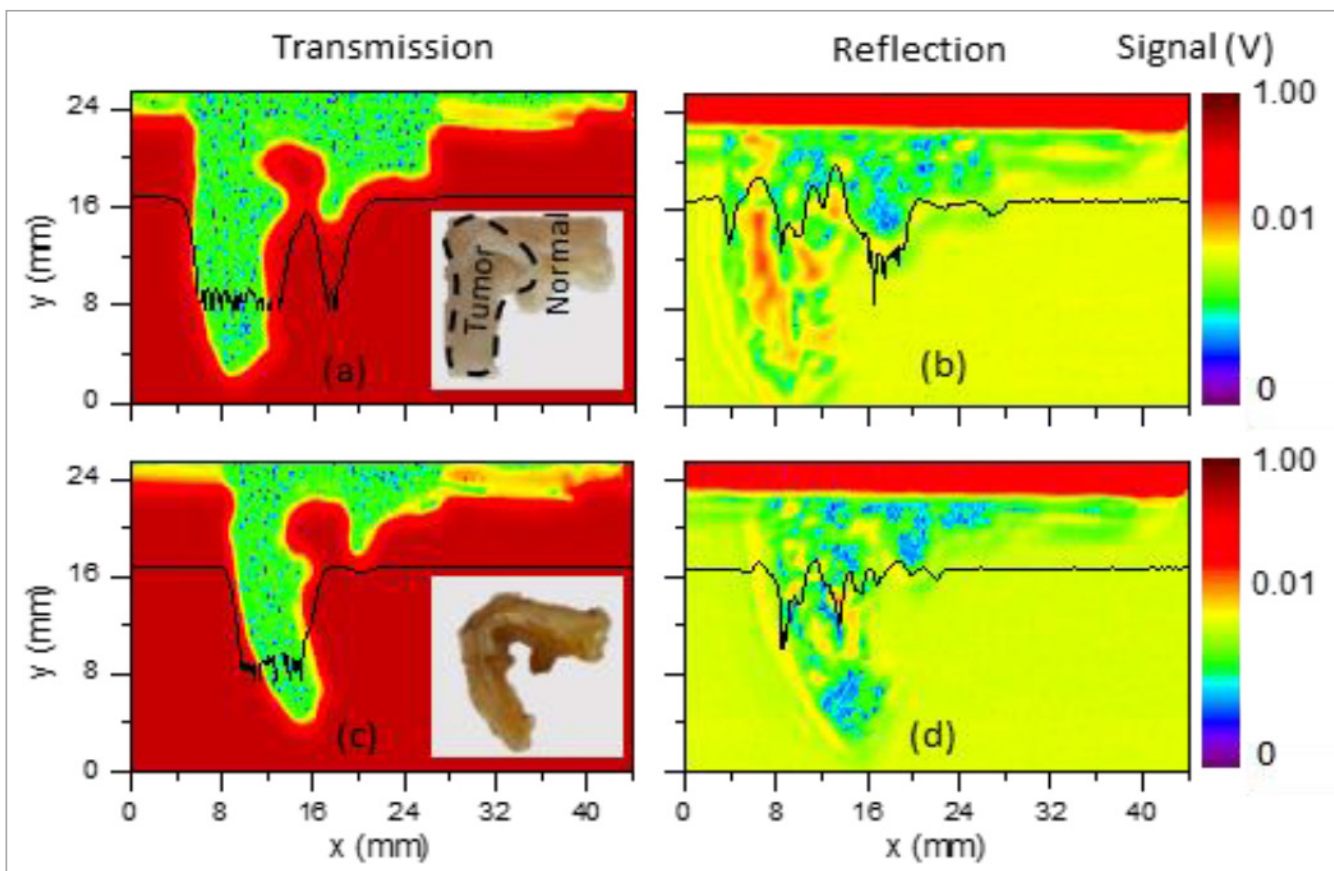

Figure 3. 0.58 THz image of the tissue from the group staged pT4. Image of the fresh tissue, taken straight from the container cell, in (a) transmission and (b) reflection configurations. Image of the tissue $24 \mathrm{~h}$ after the first measurement, in (c) transmission and (d) reflection configurations. Digital photos of the sample are shown in the insets in ( $a$ and $c$ ). Image consists of $440 \times 85$ pixels with a pixel size of $0.1 \times 0.3 \mathrm{~mm}$.

The Vilnius group acknowledges financial support from the Research Council of Lithuania under the KITKAS project, contract No. LAT-04/2016.

\section{References}

1. IARC, Press Release: Latest Global Cancer Data: Cancer Burden Rises to 18.1 million New Cases and 9.6 million Cancer Deaths in 2018. International Agency for Research on Cancer (12 September 2018). https://www.iarc.fr/wp-content/uploads/2018/09/ pr263_E.pdf

2. A.G. Markelz, "Terahertz dielectric sensitivity to biomolecular structure and function", IEEE J. Sel. Top. Quantum Electron. 14(1), 180 (2008). https://doi. org/10.1109/JSTQE.2007.913424

3. A.G. Markelz, A. Roitberg and E.J. Heilweil, "Pulsed terahertz spectroscopy of DNA, bovine serum albumin and collagen between 0.1 and 2.0 THz", Chem. Phys. Lett. 320(1-2), 42 (2000). https://doi. org/10.1016/S0009-2614(00)00227-X
4. T. Baras, T. Kleine-Ostmann and M. Koch, "On-chip THz detection of biomaterials: a numerical study", J. Biol. Phys. 29(2-3), 187 (2003). https://doi. org/10.1023/A:1024444809852

5. B. Fisher, Broadband THz Time-Domain Spectroscopy of Biomolecules, Dr.rer.nat Thesis, Albert-LudwigsUniversität Freiburg (2005).

6. J.T.A. Carriere, F. Havermeyer and R.A. Heyler, "THz-Raman spectroscopy for explosives, chemical, and biological detection", in Proc. SPIE 8710 , Chemical, Biological, Radiological, Nuclear, and Explosives (CBRNE) Sensing XIV, Baltimore, Maryland, United States, p. 87100M (2005). https://doi. org/10.1117/12.2018095

7. A.G. Davies, A.D. Burnett, W. Fan, E.H. Linfield and J.E. Cunningham, "Terahertz spectroscopy of explosives and drugs", Mater. Today 11(3), 18 (2008). https://doi.org/10.1016/S1369-7021(08)70016-6

8. L. Guo, L. Zhang, X. Wang, Y. Hu and C. Zhang, "Time-resolved terahertz spectroscopy of explosive materials", Chinese Opt. Lett 3(S1), S117 (2005).

9. I. Kašalynas, R. Venckevičius, D. Seliuta, I. Grigelionis and G. Valušis, "InGaAs-based bow-tie 
diode for spectroscopic terahertz imaging", J. Appl. Phys. 110(11), 114505 (2011). https://doi. org/10.1063/1.3658017

10. A. Dobroiu, Y. Sasaki, T. Shibuya, C. Otani and K. Kawase, "THz-wave spectroscopy applied to the detection of illicit drugs in mail", Proc. IEEE 95(8), 1566 (2007). https://doi.org/10.1109/ JPROC.2007.898840

11. Kaori Fukunaga and Marcello Picollo, "Terahertz time domain spectroscopy and imaging applied to cultural heritage", in 13th International Symposium on Nondestructive Characterization of Materials (NDCMXIII), Le Mans, France.

12. J.B. Jackson, J. Bowen, G. Walker, J. Labaune, G. Mourou, M. Menu and K. Fukunaga, "A survey of terahertz applications in cultural heritage conservation science", IEEE Trans. Terahertz Sci. Technol. 1(1), 220 (2011). https://doi.org/10.1109/ TTHZ.2011.2159538

13. T. Ervasti, P. Silfsten, J. Ketolainen and K.-E. Peiponen, "A study on the resolution of a terahertz spectrometer for the assessment of the porosity of pharmaceutical tablets", Appl. Spectrosc. 66(3), 319 (2012). https://doi.org/10.1366/11-06315

14. W. Momose, H. Yoshino, Y. Katakawa, K. Yamashita, K. Imai, K. Sako, E. Kato, A. Irisawa, E. Yonemochi and K. Terada, "Applying terahertz technology for nondestructive detection of crack initiation in a film-coated layer on a swelling tablet", Results Pharma Sci. 2, 29 (2012). https://doi.org/10.1016/j. rinphs.2012.04.001

15. C. Yu, S. Fan, Y. Sun and E. Pickwell-Macpherson, "The potential of terahertz imaging for cancer diagnosis: A review of investigations to date", Quant. Imaging Med. Surg. 2(1), 33 (2012). https://doi. org/10.3978/j.issn.2223-4292.2012.01.04

16. S.P. Mickan, A. Menikh, H. Liu, C.A. Mannella, R. MacColl, D. Abbott, J. Munch and X.-C. Zhang, "Label-free bioaffinity detection using terahertz technology", Phys. Med. Biol. 47(21), 3789 (2002). https:// doi.org/10.1088/0031-9155/47/21/317

17. J.-H. Son, "Terahertz electromagnetic interactions with biological matter and their applications", J. Appl. Phys. 105(10), 102033 (2009). https://doi. org/10.1063/1.3116140

18. V.P. Wallace, A.J. Fitzgerald, E. Pickwell, R.J. Pye, P.F. Taday, N. Flanagan and T. Ha, "Terahertz pulsed spectroscopy of human Basal cell carcinoma",
Appl. Spectrosc. 60(10), 1127 (2006). https://doi. org/10.1366/000370206778664635

19. P.C. Ashworth, E. Pickwell-MacPherson, E. Provenzano, S.E. Pinder, A.D. Purushotham, M. Pepper and V.P. Wallace, "Terahertz pulsed spectroscopy of freshly excised human breast cancer", Opt. Express 17(15), 12444 (2009). https://doi. org/10.1364/OE.17.012444

20. C. Reid, "Spectroscopic methods for medical diagnosis at terahertz wavelengths", Doctoral Thesis, University College London (2009). https://discovery. ucl.ac.uk/id/eprint/17571/

21. A.J. Fitzgerald, E. Berry, N.N. Zinov'ev, S. HomerVanniasinkam, R.E. Miles, J.M. Chamberlain and M.A. Smith, "Catalogue of human tissue optical properties at terahertz frequencies", J. Biol. Phys. 29(2-3), 123 (2003). https://doi.org/10.1023/A:1024428406218

22. S.Y. Huang, Y.X.J. Wang, D.K.W. Yeung, A.T. Ahuja, Y.T. Zhang and E. Pickwell-Macpherson, "Tissue characterization using terahertz pulsed imaging in reflection geometry", Phys. Med. Biol. 54(1), 149 (2009). https://doi.org/10.1088/00319155/54/1/010

23. E. Pickwell, B.E. Cole, A.J. Fitzgerald, M. Pepper and V.P. Wallace, "In vivo study of human skin using pulsed terahertz radiation", Phys. Med. Biol. 49(9), 1595 (2004). https://doi.org/10.1088/00319155/49/9/001

24. C.B. Reid, A. Fitzgerald, G. Reese, R. Goldin, P. Tekkis, P.S. O'Kelly, E. Pickwell-MacPherson, A.P. Gibson and V.P. Wallace, "Terahertz pulsed imaging of freshly excised human colonic tissues", Phys. Med. Biol. 56(14), 4333 (2011). https://doi. org/10.1088/0031-9155/56/14/008

25. J.E. Downing, W.M. Christopherson and W.L. Broghamer, "Nuclear water content during carcinogenesis", Cancer 15(6), 1176 (1961). https://doi.org/10.1002/10970142(196211/12)15:6<1176::AIDCNCR2820150614>3.0.CO;2-F

26. H. van Slooten, A. Schaberg, D. Smeenk and A.J. Moolenaar, "Morphologic characteristics of benign and malignant adrenocortical tumors", Cancer 55(4), 766 (1985). https://doi. org/10.1002/1097-0142(198502/15)55:4<766::AIDCNCR2820550414>3.0.CO;2-7

27. J.F. Federici, "Review of moisture and liquid detection and mapping using terahertz imaging", J. Infrared 
Millim. Terahertz Waves 33(2), 97 (2012). https://doi. org/10.1007/s10762-011-9865-7

28. F. Wahaia, I. Kasalynas, R. Venckevicius, D. Seliuta, G. Valusis, A. Urbanowicz, G. Molis, F. Carneiro, C.D. Carvalho Silva and P.L. Granja, "Terahertz absorption and reflection imaging of carcinoma-affected colon tissues embedded in paraffin", J. Mol. Struct. 1107, 214 (2016). https://doi.org/10.1016/j.molstruc.2015.11.048

29. F. Wahaia, I. Kasalynas, D. Seliuta, G. Molis, A. Urbanowicz, C.D. Carvalho Silva, F. Carneiro, G. Valusis and P.L. Granja, "Terahertz spectroscopy for the study of paraffin-embedded gastric cancer samples", J. Mol. Struct. 1079, 391 (2015). https://doi. org/10.1016/j.molstruc.2014.09.002

30. F. Wahaia, G. Valusis, L.M. Bernardo, A. Almeida, J.A. Moreira, P.C. Lopes, J. Macutkevic, I. Kasalynas, D. Seliuta, R. Adomavicius, R. Henrique and M. Lopes, "Detection of colon cancer by terahertz techniques", J. Mol. Struct. 1006(1-3), 77 (2011). https://doi. org/10.1016/j.molstruc.2011.05.049

31. D. Hou, X. Li, J. Cai, Y. Ma, X. Kang, P. Huang and G. Zhang, "Terahertz spectroscopic investigation of human gastric normal and tumor tissues", Phys. Med. Biol. 59(18), 5423 (2014). https://doi. org/10.1088/0031-9155/59/18/5423

32. L.H. Sobin, M.K. Gospodarowicz and C. Wittekind (Eds), TNM Classification of Malignant Tumours, $7^{\text {th }}$ Edn. Wiley-Blackwell (2011).

33. T.N. El-Bolkainy, M.A. Sakr, A.A. Nouh and N.H.A. El-Din, "A comparative study of rectal and colonic carcinoma: demographic, pathologic and TNM staging analysis", J. Egypt Natl. Canc. Inst. 18(3), 258 (2006). https://www.ncbi.nlm.nih.gov/pub$\mathrm{med} / 17671536$

34. A. Nahata, A.S. Weling and T.F. Heinz, "Wideband coherent terahertz spectroscopy using optical rectification and electro-optic sampling", Appl. Phys. Lett. 69(16), 2321 (1996). https://doi. org/10.1063/1.117511

35. D. Leonel, G. Fredric, R. Jean-Francois and J.-K. Coutaz, "Analytical modeling and optimization of terahertz time-domain spectroscopy experiments using photoswitches as antennas", IEEE J. Sel. Top. Quantum Electron. 7, 605 (2001).

36. H. Ying, P. Huang, L. Guo, X. Wang and C. Zhang, "Terahertz spectroscopic investigations of explosives", Phys. Lett. 359(6), 728 (2006). https://doi. org/10.1016/j.physleta.2006.07.046

37.T.D. Dorney, R.G. Baraniuk and D.M. Mittleman, "Material parameter estimation with terahertz timedomain spectroscopy", J. Opt. Soc. Am. A Opt. Image Sci. Vis. 18(7), 1562 (2001). https://doi.org/10.1364/ JOSAA.18.001562

38. W. Withayachumnankul, B.M. Fischer, H. Lin and D. Abbott, "Uncertainty in terahertz time-domain spectroscopy measurement", J. Opt. Soc. Am. B 25(6), 1059 (2008). https://doi.org/10.1364/ JOSAB.25.001059

39. J. Trontelj, G. Valušis, R. Venckevičius, I. Kašalynas, A. Sešek and A. Švigelj, "A high performance room temperature THz sensor", Proc. SPIE 9199, 91990K (2014). https://doi.org/10.1117/12.2060692

40. I. Kašalynas, R. Venckevičius, L. Minkevičius, A. Sešek, F. Wahaia, V. Tamošiūnas, B. Voisiat, D. Seliuta, G. Valušis, A. Švigelj and J. Trontelj, "Spectroscopic terahertz imaging at room temperature employing microbolometer terahertz sensors and its application to the study of carcinoma tissues", Sensors 16(4), 432 (2016). https://doi.org/10.3390/ s16040432 